\title{
Virilization of a Young Girl Caused by Concomitant Ectopic and Intra-Adrenal Adenomas of the Adrenal Cortex
}

\author{
Daniela Choukair $^{\text {a }}$ Felix Beuschlein ${ }^{d}$ Oliver Zwermann ${ }^{d}$ Stefan A. Wudy \\ Sabine Haufe ${ }^{b}$ Stefan Holland-Cunz ${ }^{c}$ Markus Bettendorf ${ }^{a}$ \\ ${ }^{a}$ Division of Pediatric Endocrinology, University Children's Hospital Heidelberg, ${ }^{b}$ Division of Nuclear Medicine, \\ Department of Radiology and 'Department of Pediatric Surgery, University of Heidelberg, Heidelberg, \\ ${ }^{\mathrm{d}}$ Department of Medicine, Endocrine Research, University Hospital Innenstadt, Ludwig Maximilians University, \\ Munich, and e Pediatric Endocrinology and Diabetology, Justus Liebig University Giessen, Giessen, Germany
}

\section{Established Facts}

- Adenomas of the adrenal gland are rare causes of virilization in childhood and are rarely located as bilateral or ectopic.

\section{Novel Insights}

- The presented case describes for the first time that virilization in a young girl is due to concomitant ectopic and intra-adrenal adenomas of the adrenal cortex. Melanocortin 2 receptor expression confirmed that the ectopic adenoma originated from the adrenal cortex.

\section{Key Words}

Adrenal adenoma $\cdot$ Ectopic adenoma - Intra-adrenal adenoma $\cdot$ Children

\section{Abstract \\ Background: Adenomas of the adrenal gland are rare causes of virilization in childhood. Case Report: A girl aged 2 years and 4 months presented with pubarche, distinct clitoral hy- pertrophy, tall stature, and increased height velocity. Plasma}

testosterone and dehydroepiandrosterone were elevated. Androgens remained unchanged after adrenocorticotropic hormone, and dexamethasone administrations. Ultrasound examination and magnetic resonance imaging indicated an extra-adrenal mass adjacent to the left adrenal gland, which was removed by endoscopic surgery. However, plasma androgens remained elevated and ${ }^{131}$ l-iodomethyl-norcholesterol scintigraphy revealed tracer enhancement in the right adrenal gland, which was consecutively removed. Virilization regressed after extirpation of the adenomas and height

\section{KARGER}

E-Mail karger@karger.com www.karger.com/hrp
(C) 2013 S. Karger AG, Basel

$1663-2818 / 13 / 0795-0318 \$ 38.00 / 0$
Daniela Choukair, MD

University Children's Hospital

Im Neuenheimer Feld 430

DE-69120 Heidelberg (Germany)

E-Mail daniela.choukair@ @ med.uni-heidelberg.de 
velocity normalized. Results: Histology revealed a circumscribed adenoma in the right adrenal gland and an epithelial mass with adrenal cortical cells in the left-sided ectopic tumor. In the ectopic tumor, melanocortin 2 receptor expression was augmented threefold compared to the control, indicating adrenal origin. Conclusions: In this young girl, virilization is due to concomitant ectopic and intraadrenal adenomas of the adrenal cortex. By melanocortin 2 receptor expression, it was confirmed that the ectopic adenoma derived from the adrenal cortex. Specific scintigraphy, if available, assists in allocating the source of androgen hypersecretion.

Copyright $\odot 2013$ S. Karger AG, Basel

\section{Introduction}

Adrenocortical tumors (ACT) are rare in children. The worldwide annual incidence ranges from 0.3 to 0.38 per million children below the age of 15 years, with $65 \%$ occurrence in children younger than 5 years $[1,2]$. In young children, the incidence of ACT seems to be higher for young girls with a female/male ratio of $2: 1$, whereas in adolescents, the female/male ratio is 1:1 [3-5]. In contrast to adults, the most frequent presentation in children with ACT is virilization, followed by hypercortisolism and hyperaldosteronism $[6,7]$. The diagnosis is supported when serum levels of dehydroepiandrosterone (DHEA), DHEA sulfate, androstenedione, and testosterone are elevated. The localization of the rather small tumors maybe difficult, especially by abdominal ultrasound. These extremely rare tumors are exceptionally located bilateral or ectopic, but to our knowledge no concomitant ectopic bilateral adrenal adenomas causing virilization in children are described in the literature $[8,9]$. To verify that the ectopic lesion is from adrenal origin detecting the expression of the melanocortin 2 (MC2) receptor could be useful [10]. Here, we report a young girl with concomitant ectopic and intra-adrenal adenomas of the adrenal cortex diagnosed by ${ }^{131}$ I-iodomethylnorcholesterol scintigraphy.

\section{Case Report}

At the age of 2 years and 4 months the girl was referred for evaluating premature pubarche. Her parents had recognized pubic hair 5 months ago. She presented with pubertal stages according to Tanner breast 1, pubic hair 3, and distinct clitoral hypertrophy, no acne, no axillary hair, and no striae [11]. The girl was tall $(102 \mathrm{~cm}$; SDS +2.94) and her height velocity was increased (10.7 $\mathrm{cm} /$ years; SDS 1.98) (fig. 1). Biochemical assessment revealed normal serum electrolytes. Basal morning plasma concentrations of 17-hydroxyprogesterone $3.12 \mathrm{nmol} / \mathrm{l}$ (reference range 0.09-2.73),

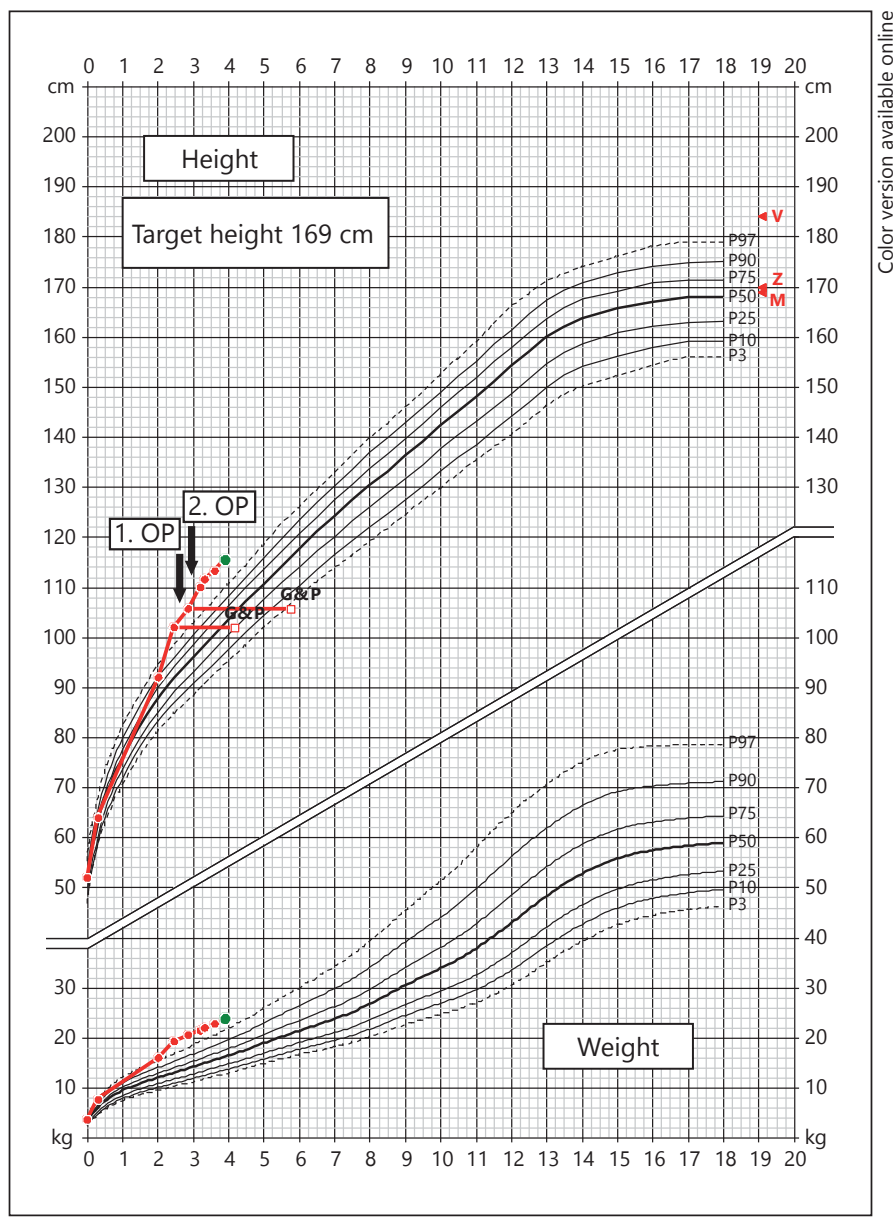

Fig. 1. Growth chart of the patient. Arrows indicate the two sequential operations.

androstenedione $4.6 \mathrm{nmol} / \mathrm{l}$ (reference range $0.17-1.75$ ), testosterone $7.08 \mathrm{nmol} / \mathrm{l}$ (reference range <0.69), DHEA $9.4 \mathrm{nmol} / \mathrm{l}$ (reference range 0.69-4.51), and DHEA sulfate $0.34 \mu \mathrm{mol} / \mathrm{l}$ (reference range $<0.052$ ) were notably elevated. The urinary steroid metabolome revealed a 2.5-fold elevated excretion rates of androgen metabolites, such as androsterone, etiocholanolone, 16-alpha-hydroxy-DHEA, 5 -androstene- $3 \beta, 17 \beta$-diol, $3 \beta, 16 \alpha, 17 \beta$-androstenetriol, $11-\mathrm{OH}$-androsterone, and testosterone. Glucocorticosteroid excretion in 24-hour urine, circadian adrenocorticotropic hormone (ACTH), and cortisol were not elevated. The bone age (Greulich and Pyle) was accelerated to $42 / 12$ years [12]. Initially, we presumed that the underlying disease was 21-hydroxylase-deficiency or other forms of virilizing congenital adrenal hyperplasia, but finally this hypothesis was excluded by ACTH test, molecular genetic analysis, and urinary steroid metabolomics analysis.

As part of the clinical work-up, abdominal ultrasound was performed, which revealed a slightly thickened right adrenal gland, while the left adrenal gland was normal. In contrast, MRI revealed an ectopic tumor in the area of the left renal hilus with a diameter of $13 \mathrm{~mm}$. Surgical excision of this ectopic lesion disclosed a beige tumor measuring $1.8 \times 1 \times 0.8 \mathrm{~cm}$. However, de-
Virilizing Ectopic and Intra-Adrenal Adenomas of the Adrenal Cortex
Horm Res Paediatr 2013;79:318-322 319 
spite the complete excision of the ectopic tumor located in the left renal hilus, testosterone and DHEA decreased approximately by $50 \%$, but were still elevated: $2.88 \mathrm{nmol} / 1$ (reference range $<0.69$ ) and $6.32 \mathrm{nmol} / \mathrm{l}$ (reference range 0.69-4.51), respectively. After oral application of $1 \mathrm{mg}$ dexamethasone plasma testosterone and DHEA were not suppressed, $1.77 \mathrm{nmol} / \mathrm{l}$ (age-adjusted female range $<0.69$ ) and $33.17 \mathrm{nmol} / \mathrm{l}$ (reference range 0.69-4.51), respectively. Abdominal ultrasound demonstrated again a slightly enlarged right adrenal gland and for specification ${ }^{131}$ I-iodomethylnorcholesterol scintigraphy was performed after administration of $1 \mathrm{mg}$ dexamethasone and sodium perchlorate. Enhancement of the tracer was clearly detectable in the right gland and total adrenalectomy of the right gland was performed. Histological examination revealed a $0.4 \times 0.6 \mathrm{~cm}$ tumor located paracentrally and reaching the mark of the adrenal gland. Subsequently, virilization regressed after removal of these two adenomas and height velocity normalized to $6.79 \mathrm{~cm} /$ year (SDS -0.96). Testosterone and DHEA decreased to the normal infantile range, 0.17 and $0.83 \mathrm{nmol} / \mathrm{l}$, respectively. Because bilateral adrenal adenomas could be associated with McCune-Albright syndrome, we excluded this disease pattern clinically in our patient.

\section{Methods}

Serum steroid hormones were determined by radioimmunoassays using tritiated steroids (Amersham Biosciences, Freiburg, Germany) and specific antibodies, raised and characterized in the steroid laboratory, as described elsewhere [13]. The urinary steroid metabolome was assessed by gas chromatography-mass spectrometry [14].

RNA was extracted from the ectopic tumor in the area of the left adrenal gland (QIAGEN, Hilden, Germany). MC2 receptor and $L H$ receptor $m R N A$ expression were investigated by quantitative PCR according to Zwermann et al. [10].

The patient's parents were informed about all the diagnostic procedures and gave their written consent for the necessary surgery, tumor removal, and analysis of tumor tissue.

\section{Results}

Histological examination of the ectopic lesion close to the left renal hilus revealed an oxyphilic epithelial tumor with a Ki67 proliferation index ranging from 2 to $5 \%$. Staining was positive for synaptophysin, melan-A, inhibin, and CD56, weak staining for calretinin. $\beta$-human chorionic gonadotropin hormone, alpha-1-fetoprotein, placental alkaline phosphatase, protein S100, and chromogranin A were not detectable. In the ectopic tumor $\mathrm{MC} 2 \mathrm{R}$ expression was threefold higher in comparison to normal adrenal glands while only low expression of the LH receptor was detected in comparison to normal adrenals (fig. 2). The intra-adrenal tumor of the right adrenal gland contained oxyphilic epithelial cells with a Ki67 pro-

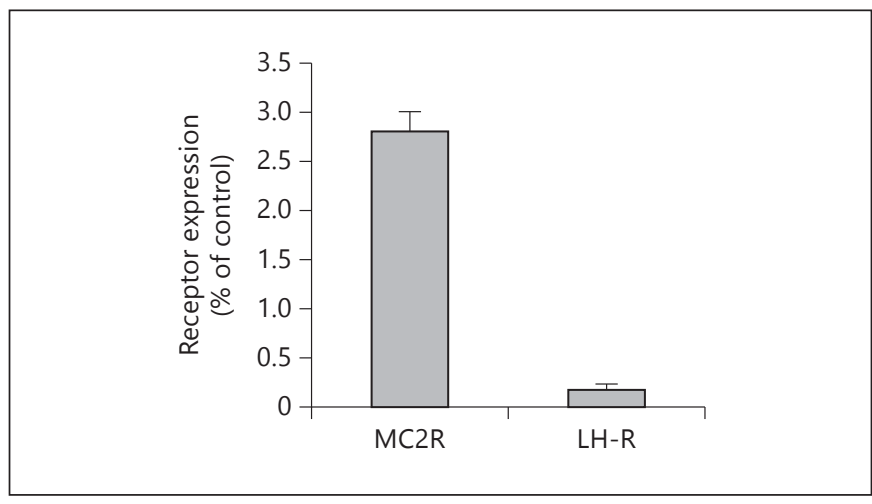

Fig. 2. Expression of mRNA (-fold) of MC2 receptor and LH receptor by PCR.

liferation index of 2-5\% and no invasion of the capsula or vessels were detected. Further immunohistochemical investigation demonstrated positive staining for synaptophysin, vimentin, melan-A, inhibin and CD56, while panzytokeratin (KL-1), calretinin, CD 31, protein S100 and chromogranin A were not detectable.

\section{Discussion}

We herein describe a young girl who presented with precocious pseudopuberty caused by concomitant ectopic and intra-adrenal adenomas of the adrenal cortex. Initially, we supposed that adrenal congenital hyperplasia was the underlying disease. Finally, this clinical picture was excluded and we presumed an adrenal tumor is causing virilization. Clinical signs of virilizing adrenal tumors in children include precocious pubic hair, hypertrophy of the penis or clitoris, acne, gynecomastia, increased height velocity, and accelerated bone age. Diagnosis is supported by measuring plasma DHEA, DHEA sulfate, androstenedione, testosterone, $17 \mathrm{OHP}$, and urinary steroids [15-18]. In addition, these hormones are also helpful as follow-up markers for detection of recurrence of the disease until puberty. The preoperative mandatory precise location of the tumors in the case of small lesions can present as a particular clinical challenge. In the presented case initial abdominal ultrasound investigations failed to detect the tumor. Furthermore, during the initial abdominal MRI only the ectopic tumor in the left renal hilus was visualized, while the procedure failed to detect the small nodule in the right adrenal gland. But after extirpation of the ectopic tumor of the left adrenal gland hyperandrogenism persisted. Because using con- 
ventional imaging techniques localization of the second tumor was not successful, ${ }^{131}$ I-iodomethylnorcholesterol scintigraphy was performed. This method has been reported to provide a higher sensitivity in localizing steroid-secreting lesions in comparison to MRI and correlates well with steroid biosynthesis [19]. However, the tracer is associated with a substantial radiation dosage and experiences in children are limited. In most European countries the production of the tracer has been terminated [20]. Recently, ${ }^{123}$ I-iodometomidate was used as a highly specific radiotracer for imaging of adrenocortical tissue [21]. Till now no publications are available in which this radiotracer was used in children. We believe therefore that the use of scintigraphy should be restricted to the rare cases in which the conventional diagnostic strategies failed. Prediagnostic treatment with dexamethasone is recommended in order to suppress the regular adrenal glands. Overall, our patient had concomitant intra-adrenal as well as ectopic adenomas of adrenal origin. Usually, hormone-secreting adenomas which are located bilaterally produce cortisol [22], bilateral ACT secreting androgens are extremely rare [23]. Uncommonly, ectopic adrenal tissue can become clinically apparent. To our knowledge, only 2 cases of an ectopic cortical adrenal mass in the thorax and behind the iliopsoas muscle, producing strictly androgens, have been reported in adults [8, 9]. Louiset et al. [24] described an ACTHindependent Cushing's syndrome with bilateral micronodular adrenal hyperplasia and ectopic adrenocortical adenoma. But the combination of ectopic and intra-adrenal adenoma-secreting androgens is not described until now. In our patient, both adenomas demonstrate common histological features. To verify that the ectopic tumor was of adrenal origin, we checked the expression of MC2R, which was readily detectable by realtime PCR. Interestingly, no suppression of androgens was observable after dexamethasone administration, despite the high expression of MC2R indicating autonomous activation of steroidogenesis. Because both tumors demonstrated the identical histological picture and androgens decreased half after the first operation we could speculate that both tumor parts contribute equally to the androgen secretion.

Ectopic adrenal tissue is estimated to occur in about $1 \%$ of the adult population and up to $50 \%$ in neonates. Usually, ectopic adrenal tissue regresses in early infancy [25]. The adrenal cortex develops from the coelomic mesoderm of the urogenital ridge during the 5th week of gestational age and separates from it during the 8th week $[26,27]$. Ectopic adrenal tissue occurs when a fragment of

Virilizing Ectopic and Intra-Adrenal

Adenomas of the Adrenal Cortex the primitive adrenal gland sheds off during development. It may rest in any visceral organ, more frequently in the kidney, liver, and gonads. Ectopic adrenal tissue may contain both cortex and medulla, if the breaking event occurs after migration of neural crest tissue into the cortex.

Assessing the malignant potential of adrenal tumors solely on the basis of pathological examination can prove to be difficult. Tumor weight and size, signs of vascular invasion and a high mitotic index are morphological signs of tumor carcinogenic potential. A tumor weight more than $100 \mathrm{~g}$ and a diameter greater than $5 \mathrm{~cm}$ are indicators of malignancy and infiltration of the surrounding tissue or presence of metastases are obvious signs for carcinoma [17, 28, 29]. In uncertain cases, even established histopathological criteria and algorithms adapted from tumors in adults generally do not allow clear classification in children [29-31].

Recently, molecular and genetic markers have been assessed for their potential to differentiate adrenocortical carcinomas from benign adenomas [30-37]. In our patient, analysis of steroid hormones revealed only hyperandrogenism. Generally, adrenal cortical carcinomas presents more commonly as a mixed Cushing-virilizing syndrome [38]. Histology investigation of both adenomas demonstrated Ki67 proliferation index of 2-5\% and no invasion of the capsula or vessels were detected. The analysis of the steroid hormones and the histological evaluation led us assume, that in our case the tumor has no malignant potential, but prolonged and vigilant follow up is absolutely necessary.

The treatment of choice for adrenal lesions with autonomous steroid secretion or signs indicative of malignancy is radical resection of the complete tumor by open abdominal or laparoscopic surgery. Long-term follow-up is advisable for detecting recurrence of the disease.

Our findings underline that androgen-producing adenomas may be located within and/or outside the adrenal cortex, and may provoke severe virilization in prepubertal girls. MC2 receptor expression in the tumor indicates the adrenal cortex's descent. Specific functional imaging, if available, can assist in allocating the source of androgen hypersecretion. Long-term follow-up is warranted to assure complete removal of the adenomas.

\section{Disclosure Statement}

The authors state that they have no conflict of interest that would prejudice its impartiality and have no potential conflict of interest that is fully declared within the text of the article. 


\section{References}

1 Latronico AC, Chrousos GP: Extensive personal experience: adrenocortical tumors. J Clin Endocrinol Metab 1997;82:1317-1324.

-2 Ribeiro RC, Sandrini F, Figueiredo B, Zambetti GP, Michalkiewicz E, Lafferty AR, DeLacerda L, Rabin M, Cadwell C, Sampaio G, Cat I, Stratakis CA, Sandrini R: An inherited p53 mutation that contributes in a tissue-specific manner to pediatric adrenal cortical carcinoma. Proc Natl Acad Sci USA 2001;98: 9330-9335.

-3 Sandrini R, Ribeiro RC, DeLacerda L: Childhood adrenocortical tumors. J Clin Endocrinol Metab 1997;82:2027-2031.

-4 Figueiredo BC, Ribeiro RC, Zambetti G, Haddad B, Pianovsky MD, Pereira RM, DeLacerda L, Sndrini R: Amplification of 9q34 in childhood adrenocortical tumors: a specific feature unrelated to ethnic origin or living conditions. Braz J Med Biol Res 2000;33 1217-1224.

5 Cagle PT, Hough AJ, Pysher TJ, Page DL, Johnson EH, Kirkland RT, Holcombe JH, Hawkins EP: Comparison of adrenal cortical tumors in children and adults. Cancer 1986;57:2235-2237.

6 Bonfig W, Bittmann I, Bechtold S, Kammer B, Noelle V, Arleth S, Raile K, Schwarz HP: Virilising adrenocortical tumours in children. Eur J Pediatr 2003;162:623-628.

7 Chen QL, Su Z, Li YH, Ma HM, Chen HS, Du ML: Clinical characteristics of adrenocortical tumors in children. J Pediatr Endocrinol Metab 2011;24:535-541.

$>8$ Mavroudis K, Aloumanis K, Papapetrou PD, Voros D, Spanos I: Virilization caused by an ectopic adrenal tumor located behind the iliopsoas muscle. Fertil Steril 2007;87:1468. e13-e16.

9 Medeiros LJ, Anasti J, Gardner KL, Pass HI, Nieman LK: Virilizing adrenal cortical neoplasm arising ectopically in the thorax. J Clin Endocrinol Metab 1992;75:1522-1525.

-10 Zwermann O, Suttmann Y, Bidlingmaier M, Beuschlein F, Reincke M: Screening for membrane hormone receptor expression in primary aldosteronism. Eur J Endocrinol 2009;160 443-451.

11 Tanner JM, Whitehouse RH: Clinical longitudinal standards for height, weight, height velocity, weight velocity, and stages of puberty. Arch Dis Child 1976;51:170-179.

12 Greulich WW, Phyle SI: Radiographic Atlas of Skeletal Development of the Hand and Wrist, ed 2. Stanford, Stanford University Press, 1959.
13 Vecsei P, Abdelhamid S, Mittelstadt GV, Lichtwald K, Haack D, Lewicka S: Aldosterone metabolites and possible aldosterone precursors in hypertension. J Steroid Biochem 1983;19: 345-351.

14 Remer T, Boye KR, Hartmann M, Neu CM, Schoenau E, Manz F, Wudy SA: Adrenarche and bone modeling and remodeling at the proximal radius: weak androgens make stronger cortical bone in healthy children. J Bone Miner Res 2003;18:1539-1546.

5 Bornstein SR: Adrenocortical tumors: recent advances in basic concepts and clinical management. Ann Intern Med 1999;130:759-771.

16 Honour JW, Price DA, Taylor NF, Marsden $\mathrm{HB}$, Grant DB: Steroid biochemistry of viril izing adrenal tumors in childhood. Eur J Pe diatr 1984; 142:165-169.

17 Lee PDK, Winter RJ, Green OC: Virilizing adrenocortical tumors in childhood: eight cases and a review of the literature. Pediatrics 1985; 76:437-443

18 Moore L, Barker AP, Byard RW, Bourne AJ, Ford WDA: Adrenal cortical tumors in childhood - clinicopathological features of six cases. Pathology 1991;23:94-97.

19 Dwamena BA, Kloos RT, Fendrick AM, Gross MD, Francis IR, Korobkin MT, Shapiro B: Di agnostic evaluation of the adrenal incidentaloma: decision and cost-effectiveness analyses. J Nucl Med 1998;39:707-712.

20 Sundin A: Imaging of adrenal masses with emphasis on adrenocortical tumors. Theranostics 2012;2:516-522.

21 Hahner S, Stuermer A, Kreissl M, Reiners C, Fassnacht M, Haenscheid $\mathrm{H}$, Beuschlein F, Zink M, Lang K, Allolio B, Schirbel A: $\left[{ }^{123} \mathrm{I}\right]$ iodometomidate for molecular imaging of adrenocortical cytochrome P450 family $11 \mathrm{~B}$ enzymes. J Clin Endocrinol Metab 2008;93: 2358-2365.

22 Stratakis CA, Boikos SA: Genetics of adrenal tumors associated with Cushing's syndrome: a new classification for bilateral adrenocortical hyperplasias. Nat Clin Pract Endocrinol Metab 2007;3:748-757

23 Goodarzi MO, Dawson DW, Li X, Lei Z, Shintaku P, Rao CV, Van Herle AJ: Virilization in bilateral macronodular adrenal hyperplasia controlled by luteinizing hormone. J Clin Endocrinol Metab 2003;88:73-77.

24 Louiset E, Gobet F, Libé R, Horvath A, Renouf S, Cariou J, Rothenbuhler A, Bertherat J, Clauser E, Grise P, Stratakis CA, Kuhn JM, Lefebvre H: ACTH-independent Cushing's syndrome with bilateral micronodular adrenal hyperplasia and ectopic adrenocortical adenoma. J Clin Endocrinol Metab 2010;95:18-24.
25 Ye H, Yoon GS, Epstein JI: Intrarenal ectopic adrenal tissue and renal-adrenal fusion: a report of nine cases. Mod Pathol 2009;22:175181.

26 Sadler TW: Langman's Medical Embryology, ed 10. Baltimore, Lippincott Williams \& Wilkins, MD, 2006, vol 68-72, pp 314-315.

27 Moore KL, Persaud TVN: The Developing Human, ed 7. Philadelphia, Saunders, 2003, pp 288-306.

28 Wolthers OD, Cameron FJ, Scheimberg I, Honour JW, Hindmarsh PC, Savage MO, Stanhope RG, Brook CGD: Androgen secreting adrenocortical tumors. Arch Dis Child 1990;80 46-50.

29 Hough AJ, Hollifield JW, Page DL, Hartmann WH: Prognostic factors in adrenal cortical tumors: a mathematical analysis of clinical and morphologic data. Am J Clin Pathol 1979;72: 390-399.

30 Saeger W: Histopathololgical classification of adrenal tumors. Eur J Clin Invest 2000;30 (suppl 3):58-62.

31 Weiss LM: Comparative histologic study of 43 metastasizing and nonmetastasizing adrenocortical tumors. Am J Surg Pathol 1984;8: 163-169.

32 Arola J, Liu J, Heikkilä P, Ilvesmäki V, Salmenkivi K, Voutilainen R, Kahri AI: Expression of inhibin alpha in adrenocortical tumors reflects the hormonal status of the hormonal status of the neoplasm. J Endocrinol 2000;165:223-229.

33 Arola J, Salmenkivi A, Liu J, Kahri Al, Heikkilä P: p53 and Ki 67 in adrenocortical tumors. Endocr Res 2000;26:861-865.

34 Heppner C, Reincke M, Agrawal SK, Mora P Allolio B, Burns AL, Spiegel AM, Marx SJ: MEN1 gene analysis in sporadic adrenocortical neoplasms. J Clin Endocrinol Metab 1999; 84:216-219.

35 Pelkey TJ, Frierson HF, Mills SE, Stoler MH The alpha subunit of inhibin in adrenal cortical neoplasia. Mod Pathol 1998;11:516-524.

36 Reincke M: Mutations in adrenocortical tumors. Horm Metab Res 1998;30:447-455.

37 Fottner CH, Hoeflich A, Wolf E, Weber MM: Role of the insulin-like growth factor system in adrenocortical growth control and carcinogenesis. Horm Metab Res 2004;36:397-405.

-38 Wajchenberg BL, Albergaria Pereira MA, Medonca BB, Latronico AC, Campos Carneiro P, Alves VA, Zerbini MC, Liberman B, Carlos Gomes G, Kirschner MA: Adrenocortical carcinoma: clinical and laboratory observations. Cancer 2000;88:711-736. 